\title{
Serum Concentration of Immunoglobulin Classes and Subclasses in Macedonian Elderly People
}

\author{
Meri Kirijas $^{1}$, Slavica Hristomanova ${ }^{1}$, Dejan Trajkov${ }^{1}$, Milanka Pajkovska², Berislav Kostov², Mirko Spiroski ${ }^{1}$ \\ ${ }^{1}$ Institute of Immunobiology and Human Genetics, Faculty of Medicine, University "Ss. Cyril and Methodius", Skopje, Republic of \\ Macedonia; ' Gerontology Department "13 Noemvri", Skopje, Republic of Macedonia
}

\begin{abstract}
Citation: Kirijas M, Hristomanova S, Trajkov D, Pajkovska M, Kostov B, Spiroski M. Serum Concentration of Immunoglobulin Classes and Subclasses in Macedonian Elderly People. Maced J Med Sci. 2012 Jut 31; 5(2):164-168. htp/ J Med Sci. 2012 Jul 31; 5/2):164-168. htep://

Key words: serum immunoglobulin levels; elderly persons: SENIEUR protocol: Republic of Macedonia.

Correspondence: Mirko Spiroski, MD, PhD. Institute of Immunobiology and Human Genetics, Faculty of Medicine, 1109 Skopje, PO Box 60, Republic of Macedonia. Phone: +38923110556 E-mail: mspiroski@yahoo.com

Received: 02-May-2012; Revised: 10-May-2012 Accepted: 20-June-2012; Online first: 02-Jul-2012

Copyright: (c) 2012 Kirijas M. This is an open access article distributed under the terms of the Creative Commons Attribution License, which permits unrestricted use, distribution, and (1) distribution, and reproduction in any medium, provided the

Competing Interests: The authors have declared that no competing interests exist.
\end{abstract}

\section{Abstract}

Aim: The aim of this study was to determine the serum concentrations of immunoglobulin classes (IgA, $\lg M$ and $\lg G$ ) and subclasses (IgG1, IgG2, IgG3 and IgG4) in elderly individuals from the Republic of Macedonia.

Material and Methods: This study included elderly persons from the Gerontology Department "13 Noemvri", Skopje, Republic of Macedonia between the ages of 65 and 101 years, previously screened with the SENIEUR protocol. We investigated the serum concentration of immunoglobulin classes (IgA, $\lg M$ and $\lg G$ ) and subclasses ( $\lg G 1, \operatorname{lgG} 2$, IgG3 and $\lg G 4$ ) in these two groups by immunonephelometry.

Results: The results have shown significantly higher concentration in the NON-SENIEUR group for the $\lg A, \lg G, \lg G 1$, and $\lg G 2$. Serum concentration of immunoglobulin classes and subclasses in the SENIEUR group have shown significantly higher values in males for IgG, IgG1, and IgG2 and in the NON-SENIEUR group significantly higher values in females for IgG, and IgG1.

Conclusion: Macedonian elderly people from NON-SENIEUR group have shown significantly higher serum concentration of $\lg A$, IgG, IgG1, and IgG2 but without differences in IgM, IgG3 and IgG4. There was gender difference in the serum immunoglobulin concentration between SENIOUR and NONSENIOR elderly group.

\section{Introduction}

Aging is a natural process, part of everyone's life. There are many physiological and pathological changes that occur in elderly persons. One of them is changes in the immune system. Many researches investigated different immunological parameters and found many age-dependent changes but the reason for these changes and the potential pathological effects are not entirely known.

Disease is frequent in ageing, and the many conflicting results in studies of the ageing process can be due to the presence of factors such as underlying disease or the use of medication. One of the main reasons is the selection of the subjects to be studied. For immunogerontology, a solution to this problem was initiated in 1984 by a working party of EURAGE, the European Community's Concerted Action Programme on Ageing and Diseases. A protocol defining strict admission criteria to studies of ageing, the SENIEUR protocol, was elaborated [1]. This protocol establishes strict admission criteria for immunogerontological studies 
Kirijas et al. Immunoglobulin Classes and Subclasses in Macedonian Elderly People

in man based on clinical information and laboratory data, and it sets limits to pharmacological interference. This protocol intends to limit the influence of disease and/or medication and to standardize admission criteria to immunogerontological studies [2].

The number of lymphocytes is decreasing with aging, neutrophils are increasing and no change is observed in the number of monocytes, basophils and eosinophils. It's known that the number of memory $\mathrm{T}$ cells (CD40RO) increases during life and the number of naive $T$ cells (CD40RA) decreases [3]. To exclude changes based on illnesses or chronical diseases, the SENIEUR protocol is performed, which defines "healthy elderly people". Monocytes, eosinophils and basophils are without change during life, whereas the number of neutrophils and natural killer (NK) cells increase with aging. T- and B-lymphocytes are diminished in number as well as in function. The serum levels of immunoglobulins are mostly increased. The balance between TH1- and TH2-cells is disturbed and also TH1and $\mathrm{TH} 2$-specific cytokines. There are also differences in the immunoglobulin concentrations and the capacity of leukocytes from the elderly to produce cytokines [4].

In comparison with SENIEUR individuals aged 25-34 years, a slight increase in IgM and IgA levels was observed from the age 35 to 44 onwards and in IgG1 from the age 55 to 64 onwards. The non-SENIEUR persons differed from their SENIEUR age-matched counterparts mainly by the elevated IgG2 and IgA levels [5]. Another study in SENIEUR-approximated subjects demonstrates an apparent decrease in Hsp60 and Hsp70 with increasing age that does not appear to be related to anti-heat shock protein antibody status. These findings support in vitro work that demonstrates an age-related reduced ability to respond to stress [6].

The aim of our study was to determine the serum concentrations of immunoglobulin classes (IgA, $\lg M$ and $\lg G$ ) and subclasses (IgG1, IgG2, IgG3 and IgG4) in elderly individuals in the Republic of Macedonia.

\section{Material and Methods}

\section{Subjects}

This study involved several groups of elderly persons (> 65 years), all of Caucasoid origin, grouped according to age and health status. Their health status was thoroughly screened in accordance with the SENIEUR protocol applied for immunological studies [1, 2]. This protocol details exclusion criteria based on
Table 1: Exclusion Criteria for Admission to Immunogerontological Studies.

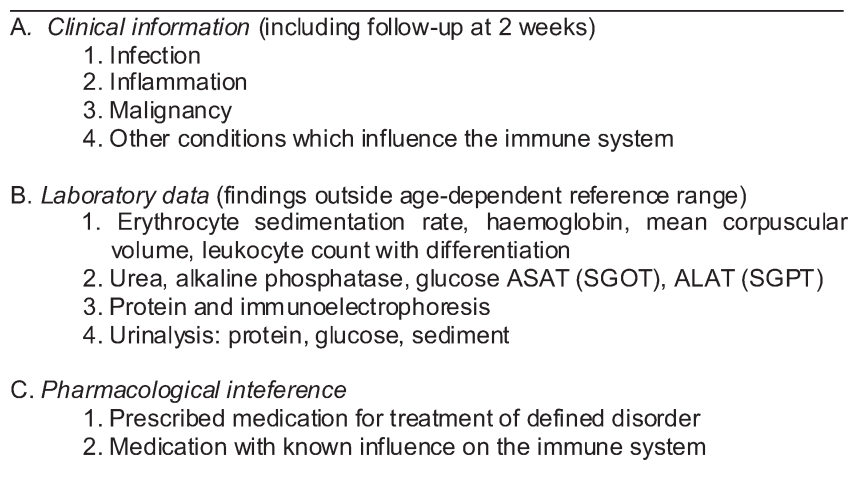

clinical information, laboratory data, and sets rules for the limitation of pharmacological interference (Table 1).

Excluded are: infection; inflammation; malignancy, past and present; other overt disease and all conditions known to influence the immune system (cardiac insufficiency, diabetes, malnutrition). Also, subjects taking medications with known influence on the immune system and subjects using any medication prescribed for the treatment of a defined disorder are excluded. The laboratory tests leading to exclusion are interpreted wherever possible with age-dependent reference values and include a haematological screening, hepatic and renal function tests and a urinanalysis.

In total, 77 elderly persons from the Gerontology Department "13 Noemvri", Skopje, Republic of Macedonia between the ages of 65 and 101 years participated in this study, screened with the SENIEUR protocol. The 53 subjects fulfilling the protocol were designated the SENIEUR group, and the 24 not conforming, the NON-SENIEUR group.

Age and sex characteristics of all groups are presented in Table 2. Elderly people from SENIEUR $(80.55 \pm 7.25$ versus $76.62 \pm 8.50$ years, $p<0.05)$. Other characteristics are none significantly different.

Table 2: Characteristics of Aged People.

\begin{tabular}{cllll}
\hline & Number & Mean age (years) & $\mathbf{p}$ & p1 \\
\hline SENIEUR & 53 & $80.55 \pm 7.25^{\star}$ & & \\
F & 37 & $79.92 \pm 7.16$ & & \\
M & 16 & $82.00 \pm 7.46$ & & NS \\
NON-SENIEUR & 24 & $76.62 \pm 8.50$ & $<0.050$ & \\
F & 14 & $75.57 \pm 9.08$ & & \\
M & 10 & $78.10 \pm 7.83$ & & NS
\end{tabular}

*Each number is mean \pm standard deviation of the mean. $p$, statistical significance between the SENIEUR and NON-SENIEUR groups; p1, statistical significance between the female and male subjects; NS, non-significant difference; $F$, female; $M$, male. 


\section{Methods}

Serum concentration of immunoglobulin classes(IgA, IgM, and $\lg G)$ and subclasses (IgG1, Ig 2 , IgG3 and IgG4) were analysed by immunonephelometry with Dade-Behring Nephelometer Analyzer [7]. External quality assessment scheme for IgG subclasses was used from United Kingdom External Quality Assessment Scheme (UKNEQAS) for immunology and immunochemistry.

\section{Statistical analysis}

All results are expressed as the mean \pm standard deviation of the mean. The group means were compared by Student $\mathrm{t}$-test, and $\mathrm{p}$ values less than 0.05 were considered significant.

\section{Results}

Serum concentration of immunoglobulin classes and subclasses in elderly persons have shown significantly higher concentration in the NON-SENIEUR group for the $\operatorname{IgA}(2.90 \pm 1.78$ versus $3.89 \pm 1.19, \mathrm{p}$ $<0.005)$, IgG $(11.13 \pm 2.73$ versus $15.14 \pm 3.84, p$ $<0.001)$, IgG1 (6.67 \pm 2.18 versus $8.30 \pm 2.49, p<0.005)$, and $\operatorname{lgG} 2(3.13 \pm 1.17$ versus $3.77 \pm 1.59, p<0.050)$. Serum concentration of the $\operatorname{lgM}, \operatorname{lgG} 3$, and IgG4 was not significantly different between SENIEUR and NONSENIEUR group of patients (Table 3 ).

Table 3: Concentration of Immunoglobulin Classes and Subclasses in Aged People of Republic of Macedonia According the SENIEUR Protocol.

\begin{tabular}{llll}
\hline & $\begin{array}{l}\text { SENIEUR } \\
(\mathrm{n}=53)\end{array}$ & $\begin{array}{l}\text { NON-SENIEUR } \\
(\mathrm{n}=24)\end{array}$ & $\mathrm{p}$ \\
\hline $\lg A(\mathrm{~g} / \mathrm{L})$ & $2.90 \pm 1.78$ & $3.89 \pm 1.19$ & $<0.005$ \\
$\operatorname{lgM}(\mathrm{g} / \mathrm{L})$ & $1.00 \pm 0.51$ & $1.22 \pm 0.84$ & $\mathrm{NS}$ \\
$\operatorname{lgG}(\mathrm{g} / \mathrm{L})$ & $11.13 \pm 2.73$ & $15.14 \pm 3.84$ & $<0.001$ \\
$\operatorname{lgG}(\mathrm{g} / \mathrm{L})$ & $6.67 \pm 2.18$ & $8.30 \pm 2.49$ & $<0.005$ \\
$\operatorname{lgG}(\mathrm{g} / \mathrm{L})$ & $3.13 \pm 1.17$ & $3.77 \pm 1.59$ & $<0.050$ \\
$\lg 3(\mathrm{~g} / \mathrm{L})$ & $0.49 \pm 0.21$ & $0.48 \pm 0.30$ & $\mathrm{NS}$ \\
$\lg 4(\mathrm{~g} / \mathrm{L})$ & $0.61 \pm 0.44$ & $0.77 \pm 0.61$ & $\mathrm{NS}$ \\
\hline
\end{tabular}

Analysis of the serum concentration of immunoglobulin classes and subclasses in elderly female and male subjects did not show significant differences (Table 4).

However, serum concentration of immunoglobulin classes and subclasses in the SENIEUR group have shown significantly higher values in males for IgG, IgG1, and IgG2 $(p<0.05)$ in comparison with females. Serum concentration of other immunoglobulin
Table 4: Concentration of Immunoglobulin Classes and Subclasses in Female and Male Aged People of Republic of Macedonia.

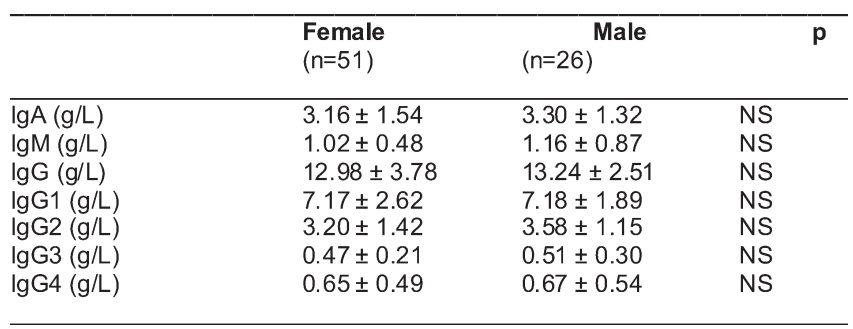

classe and subclasses (IgA, IgM, IgG3, and IgG4) were not statistically different between the female and male subjects (Figure 1).

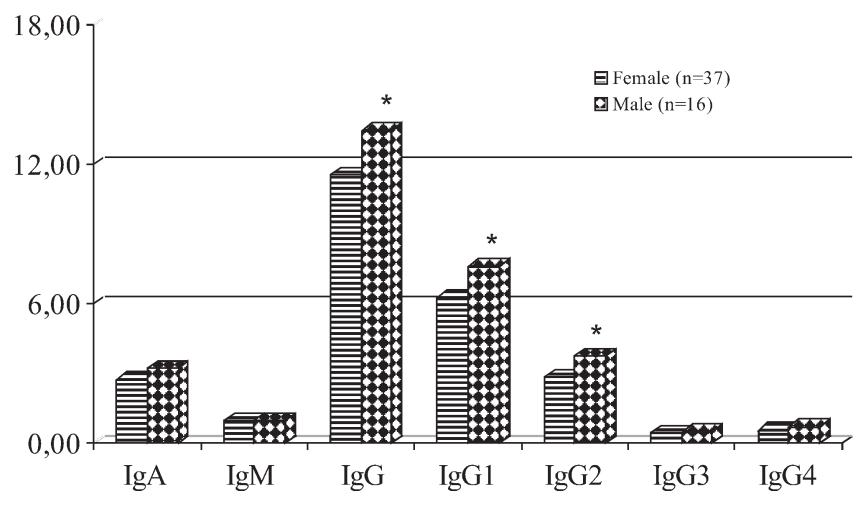

Figure 1: Serum concentration of immunoglobulin classes and subclasses $(g / L)$ in female and male subjects fulfilling the SENIEUR protocol. *, statistically significant difference.

Serum concentration of immunoglobulin classes and subclasse in the NON-SENIEUR group have shown significantly higher values in females for IgG, and IgG1 $(p<0.01$, and $p<0.001$ respectively) in comparison with males. Serum concentration of other immunoglobulin

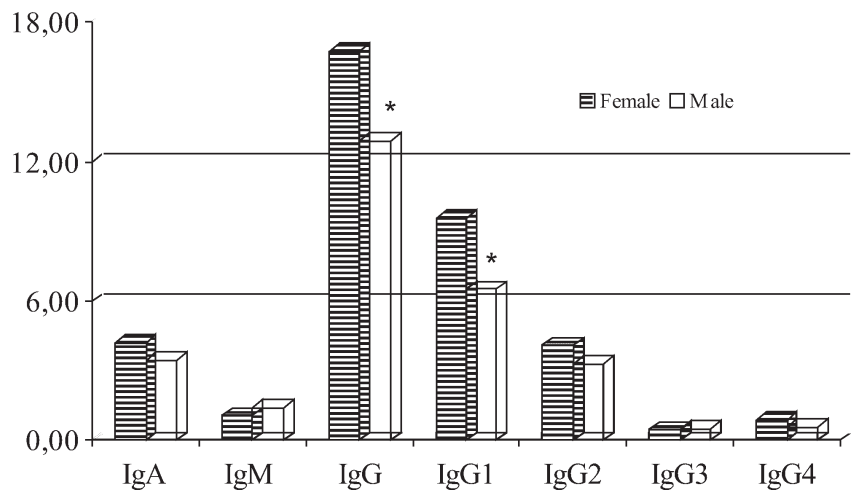

Figure 2: Serum concentration of immunoglobulin classes and subclasses $(g / L)$ in female and male subjects in the NON-SENIEUR group. *, statistically significant difference. 
classes and subclasses (IgA, IgM, IgG2, IgG3, and IgG4) were not statistically different between the female and male subjects (Figure 2).

\section{Discussion}

In this study we examined 77 elderly persons from the Gerontology Department "13 Noemvri", Skopje, Republic of Macedonia between the ages of 65 and 101. To exclude the alterations of the immune system due to illness or chronic diseases we performed SENIEURProtocol and 53 subjects fulfilling the protocol were designated the SENIEUR group, and the 24 not conforming, the NON-SENIEUR group. We measured the levels of immunoglobulin classes and subclasses in the both groups and found that there is significantly higher concentration of IgA, IgG, IgG1 and IgG2 in the NON-SENIEUR group of elderly people and no significant difference between the two groups in the concentration of $\lg M, \lg G 3$ and $\lg G 4$.

De Greef GE et al., 1992 [5] determined the serum levels of $\lg M$ and $\lg A$ classes and of $\lg G$ subclasses in volunteers at the age of 25 to 98 years, who all met the SENIEUR admission criteria for immunogerontological studies. They found that the NONSENIEUR persons differed from their SENIEUR agematched counterparts mainly by the elevated IgG2 and IgA levels. Our results are in agreement with the previous one, but we found significant differences for IgG and $\lg \mathrm{g}_{2}$. The variability of the immunoglobulin concentrations increased during ageing and the most prominent observation was the continuous decline of serum IgD starting in young adults [5].

Rink and Seyfarth, 1997 [3] investigated different immunological characteristics in three groups of individuals: healthy young and elderly screened with SENIOUR-Protocol and centenarians. They found that the serum levels of the immunoglobulin's $G, M$ and $A$ increased with age, as well as the number of benign monoclonal gammopathies and the number of autoantibodies. They also found that the number of lymphocytes decreased and the number of neutrophils increased with aging.

In spite of the lack of significant differences in the serum concentration of immunoglobulin classes and subclasses in elderly people as a group, serum concentration of immunoglobulin classes and subclasses in the SENIEUR group have shown significantly higher values in males for $\lg$, $\lg G 1$, and $\lg G 2$ and in the NON-
SENIEUR group significantly higher values in females for IgG, and IgG1. Gender differences in the concentration of immunoglobulin classes and subclasses in the SENIEUR and NON-SENIEUR groups could not be compared with other results, because, to our knowledge, there are not published similar papers. We suppose that elderly males are less immune in comparison with elderly females.

Several authors published results of the specific immunologic responses in the elderly people. Peripheral blood lymphocytes from 260 "apparently healthy" males and females, aged 20-97, have been investigated for age-related changes in a number of immunological parameters. Data were then reassessed after exclusion of people who did not conform to the SENIEUR PROTOCOL admission criteria in order to investigate whether the differences observed were attributable to underlying disease. A slight decrease in the number and percentage of lymphocytes, OKT 4+ and especially OKT $8+$ cells was found [8]. In order to explore the humoral primary and secondary response to tetanus toxoid (TT), and to define the possible immunopotentiating effect of the thymic hormone thymostimulin, authors studied 13 elderly people, selected according to the SENIEUR Eurage protocol, vaccinated against TT, an antigen never encountered before. Specific anti-TT antibody level measurement and spectrotypic analysis were performed on the sera collected from the subjects at different times over the immunization protocol. Only one patient showed a detectable humoral immune response after the first immunization. After the booster, four of six thymostimulin-treated individuals, compared with only two of seven controls, showed in vivo anti-TT humoral response. At the same time, spontaneous anti-TT production was detected in peripheral blood mononuclear cells from five of six thymostimulin-treated individuals but only three of seven untreated controls [9]. It was found that naive helper T cell numbers (CD4+ CD45RA+) were negatively correlated with antibody production to two of the four strains investigated in JUNIEURS only. By contrast, memory helper $\mathrm{T}$ cell numbers (CD4+CD45ROhi) were positively correlated with in vivo IgG antibody titres to three of the four vaccine strains. Age-related differences in the composition of the helper T cell compartment, however, did not explain the lower IgG antibody response that was observed to two of the four vaccine strains examined [10].

Seventy-seven centenarians, 70 adult controls, 65 unselected elderly subjects, and 38 old SENIEUR volunteers were investigated for anti-cardiolipin, anti- 
human beta 2 glycoprotein I, and lupus anticoagulant. Centenarians display high reactivity against human beta 2 glycoprotein I but low binding to the bovine molecule in the anti-cardiolipin assay. In spite of the presence of antibodies comparable to those found in patients with the anti-phospholipid syndrome, no vascular events were reported suggesting the presence of unknown protective factors and/or the lack of triggering factors [11].

Authors examined 154 individuals during the epidemic season dividing them according to the age, response to the vaccine and the SENIEUR Protocol $(\mathrm{SP})$. The anti-hemagglutinins $(\mathrm{HI})$, tumour necrosis factor alpha (TNFalpha), interleukin (IL) 1beta, IL6, IL10, ACTH/cortisol axis, anti-CMV antibodies and CD28+CD57- lymphocytes were assessed. The antiinfluenza vaccine induced increase in TNFalpha and IL10 in the all non-responders, while cortisol increased only in the young. They concluded that CMV carrier status eliciting elevated proinflammatory potential could contribute to unresponsiveness to the anti-influenza vaccine [11].

Our study is subject to limitations. There are huge number of publications connected with serum immunoglobulin concentration and immune response of the elderly people, but without selection according SENIEUR protocol. We included in these paper results of the SENIEUR and NON-SENIEUR differentiated elderly people and compares our result with those using similar classification, which could be understood as biased approach.

As a conclusion, the concentrations of immunoglobulin classes (IgA and IgG) and subclasses (IgG1 and IgG2) are present in significantly higher concentration in the serum of the NON-SENIEUR group of elderly persons than the SENIEUR group.

\section{References}

1. Ligthart GJ, Corberand JX, Fournier C, Galanaud P, Hijmans W, Kennes B, Müller-Hermelink HK, Steinmann GG. Admission criteria for immunogerontological studies in man: the SENIEUR protocol. Mech Ageing Dev. 1984;28(1):47-55.

2. Ligthart GJ, Corberand JX, Geertzen HG, Meinders AE,
Knook DL, Hijmans W. Necessity of the assessment of health status in human immunogerontological studies: evaluation of the SENIEUR protocol. Mech Ageing Dev. 1990;55(1):89-105.

3. Rink L, Seyfarth M. [Characteristics of immunologic test values in the elderly]. Z Gerontol Geriatr. 1997 MayJun;30(3):220-5.

4. Ibs KH, Rink L. [The immune system in aging]. Z Gerontol Geriatr. 2001;34(6):480-5.

5. De Greef GE, Van Tol MJ, Van Den Berg JW, Van Staalduinen GJ, Janssen CJ, Radl J, Hijmans W. Serum immunoglobulin class and IgG subclass levels and the occurrence of homogeneous immunoglobulins during the course of ageing in humans. Mech Ageing Dev. 1992;66(1):2944.

6. Rea IM, McNerlan S, Pockley AG. Serum heat shock protein and anti-heat shock protein antibody levels in aging. Exp Gerontol. 2001;36(2):341-52.

7. Hamilton RG. Human IgG subclass measurements in the clinical laboratory. Clin Chem, 1987;33/10:1707-1725.

8. Traill KN, Schönitzer D, Jürgens G, Böck G, Pfeilschifter R, Hilchenbach M, Holasek A, Förster O, Wick G. Age-related changes in lymphocyte subset proportions, surface differentiation antigen density and plasma membrane fluidity: application of the eurage senieur protocol admission criteria. Mech Ageing Dev. 1985;33(1):39-66.

9. Fagiolo $U$, Amadori A, Biselli R, Paganelli R, Nisini R, Cozzi E, Zamarchi R, D'Amelio R. Quantitative and qualitative analysis of anti-tetanus toxoid antibody response in the elderly. Humoral immune response enhancement by thymostimulin. Vaccine. 1993;11(13):1336-40.

10. Remarque EJ, Nijhuis EW, Hinloopen B, Nagelkerken L, van der Velde EA, Ligthart GJ. Correlation between the antibody response to influenza vaccine and helper $T$ cell subsets in healthy aging. Vaccine. 1996;14(2):127-30.

11. Meroni PL, Mari D, Monti D, Coppola R, Capri M, Salvioli S, Tincani A, Gerli R, Franceschi C. Anti-beta 2 glycoprotein I antibodies in centenarians. Exp Gerontol. 2004;39(10):145965.

12. Trzonkowski P, Myœliwska J, Szmit E, Wieckiewicz J, Lukaszuk K, Brydak LB, Machaª M, Myœliwski A. Association between cytomegalovirus infection, enhanced proinflammatory response and low level of anti-hemagglutinins during the antiinfluenza vaccination-an impact of immunosenescence. Vaccine. 2003;21(25-26):3826-36. 